Article

\title{
Categorization of the Condition of Railway Embankments Using a Multi-Attribute Utility Theory
}

\author{
Meho Saša Kovačević ${ }^{1}$, Mario Bačić ${ }^{1, *(D)}$, Irina Stipanović ${ }^{2}$ and Kenneth Gavin ${ }^{3}$ \\ 1 Faculty of Civil Engineering, University of Zagreb, 10000 Zagreb, Croatia; msk@grad.hr \\ 2 Faculty of Engineering Technology, University of Twente, 7500 AE Enschede, The Netherlands; \\ i.stipanovic@utwente.nl \\ 3 Faculty of Civil Engineering and Geosciences, TU Delft, 2628 CN Delft, The Netherlands; \\ k.g.gavin@tudelft.nl \\ * Correspondence: mbacic@grad.hr; Tel.: +385-1-4639-636
}

Received: 9 October 2019; Accepted: 22 November 2019; Published: 25 November 2019

\begin{abstract}
In the current economic climate, it is crucial to optimize the use of all resources regarding railway infrastructure maintenance. In this paper, a multi-attribute decision support framework is applied to categorize railway embankments in order to prioritize maintenance activities. The paper describes a methodology to first determine the current condition of embankments using a combination of ground penetrating radar (GPR) surveys, visual inspection, and historical data about maintenance activities. These attributes are then used for the development of a multi-attribute utility theory model, which can be used as a support for decision making process for maintenance planning. The methodology is demonstrated for the categorization of $181 \mathrm{~km}$ of railway embankments in Croatia.
\end{abstract}

Keywords: railway embankment; condition assessment; ground penetrating radar; multi-attribute utility theory

\section{Introduction}

A significant part of the major infrastructure on European railway networks was built in the 19th century, prior to the advent of modern design standards and specifications. Increased axle loading, aging, and climate impacts are known stressors to this infrastructure. In many parts of Europe, rainfall patterns are changing, in that longer dry spells are followed by periods of intense precipitation. Aged railway embankments are extremely vulnerable to the impact of such events, as drying and cracking of near surface soils during dry periods allows rapid infiltration of water during rainfall, thereby reducing the soil strength and causing sudden failure [1].

The current approach for planning maintenance works on railway infrastructure is mostly reactive [2], since infrastructure managers usually do not have sufficient information and accurate models to assess and predict the condition. Forensic analyses of historic failures often reveal that indicators of distress were ignored due to lack of understanding or the absence of a proper framework for decision-making [3]. The decisions to perform maintenance are based mostly on visual observations, subjective judgments, and choices which are ruled by available budgets, planned schedules, or abrupt failures $[4,5]$. Decisions based on these drivers often lead to undue maintenance and increased cost. Reactive maintenance should be avoided and railway agencies across the world are trying to move toward proactive maintenance planning, which would ensure safer, cost-effective, and improved network availability and reduce environmental impacts. The optimization of maintenance activities regarding technical and economic requirements is essential for transport infrastructure owners to fulfill societal expectations. Due to the long life time of rail infrastructure, especially engineering 
structures (often longer than 50 years), the assessment of technical and economic performance is necessary in order to optimize budget expenditure. Life cycle cost (LCC) analysis is a well-established methodology for the identification and assessment of maintenance trade-offs [6-9]. Nevertheless, in order to predict maintenance interventions accurately, it is necessary to assess the current condition and predict the future performance. Through early identification of problems or hot-spot locations, low-cost remediation can be applied and thus costs can be reduced and failures avoided.

The overall aim of the study is to develop a multi-attribute decision-making model to enable categorization of the condition of railway embankments across a network through the development of a ranking list. The steps involved in the categorization methodology are given within the paper. As a first step, several attributes are identified, and these include data from visual inspections and maintenance records available from the railway agency, as well as the information gathered by geophysical testing using a ground-penetrating radar. Ground Penetrating Radar (GPR) is a non-destructive tool that is widely implemented by railway owners, for example, to detect ballast fouling [10], ballast pockets [11], anomalies such as animal burrows [12], and the water content of the soil [13]. It has also been applied in a number of studies of embankment condition $[14,15]$. The method is affected by some limitations, primarily related to the reliability of results, which is dependent on the set-up of the equipment and the knowledge and experience of the operators and those analyzing and interpreting the data. Despite these limitations, the rapid and non-destructive nature of GPR investigations makes the method ideal for the categorization of embankments. After evaluating the selected attributes on the investigated line, we utilize the multi-attribute utility theory to develop a categorization procedure to be used for proactive decision-making related to the maintenance of railway embankments. The developed Multi Attribute Utility Theory (MAUT) based methodology is applied for the categorization of 181 $\mathrm{km}$ of railway embankments in Croatia, located along 18 railway lines. The results presented in the paper clearly demonstrate the potential of the methodology to ensure maximum return for use of the limited financial resources available. By defining the level of safety and potential risks that may arise, an optimized program of maintenance planning was developed, including additional investigation works, monitoring, and/or remedial measures. Further, a secondary advantage of application of complex decision-making processes in infrastructure management is to increase the attraction of traditional engineering disciplines to students with an interest in Information and Communications Technology (ICT) [16,17].

\section{Methodology}

\subsection{The Multi-Attribute Utility Theory (MAUT)}

Implicit in any decision-making process is the need to construct either directly or indirectly, the preference order, so that alternatives can be ranked and the best alternative can be selected. For some decision-making problems, this may be easily accomplished. For example, in case of a decision based on a cost-minimization rule (where the lowest cost alternative is chosen), the preference order is adequately represented by the natural order of real numbers, representing costs. Hence, in such a case, the preference order need not be constructed explicitly [18].

Multi-criteria decision-making (MCDM) provides a systematic approach to evaluate multiple conflicting attributes in decision-making. Conflicting attributes usually arise when evaluating options, for example, minimizing costs while maximizing performance. MCDM is used to identify and quantify decision-makers' and stakeholders' considerations about various (mostly) non-monetary factors, in order to compare alternative courses of action [19]. The multiple performance attribute can be combined into a so-called utility function, in which all the attributes are brought into a single scale [20]. One of the decision-making techniques that attempts to construct the preference order by directly eliciting the decision maker's preference and using multiple attributes is known as the multi-attribute utility theory (MAUT). The assumption is that a decision maker, who must select one alternative from a recognized set of decision alternatives, will be governed by preferences. In order to build 
a model which will represent the decision maker's preference and implement different attributes, a real-valued function called the utility function has to be determined for each attribute $[19,20]$. Once the functions are constructed, the selection of the appropriate alternative can be done using an optimization method. This technique involves several steps [21], including the definition of objectives and constraints, followed by the definition of attributes and by the development of a single utility function for each of the selected attributes. By assigning relative weights to the multiple attributes, an amalgamation step follows, which includes combining the single criterion utility functions using the relative weights into one measure based on mathematical assumptions about the decision maker's preference structure. Cerić [22] states that MAUT is used in cases when the best alternative solution must be chosen, i.e., for compiling a ranking list of the alternatives offered.

MAUT has been widely used in decision-making processes in the transportation infrastructure domain. Several papers consider the application of theory in the transport sector for the multi-objective optimization of multi-alternative decisions [23], the assessment of quality in bridge construction [24], road bridge management [25], or the development of a rating model that incorporates a wide range of factors affecting flexible pavements [26]. Several publications also address the implementation of MAUT in the railway sector for selecting transportation corridors linked to a traffic simulation model [27], selecting railway lines for reconstruction [28], or railway route planning and design [29]. Additional papers consider civil engineering infrastructure assets, where MAUT is incorporated in maintenance decision-making [21,30,31]. In order to implement MAUT for the categorization of railway embankments, a selection of proper attributes and alternatives shall be conducted.

\subsection{Selection of Attributes}

The aim of the proposed methodology is to improve the process of prioritization of multiple assets by taking into account multiple attributes. The model makes use of existing data available from railway agencies and improves the quality of information by including the results of non-destructive GPR inspection results. Therefore, the attributes which represent historical performance (maintenance data), experts' judgment on the condition (visual inspection), and GPR inspection results are selected. In total five attributes are selected, and the quantification of each attribute is in the range 0 to 1 . For each of the attributes, it is important to define the so called 'quantification starting value' (QSV), since it provides clear quantification procedure, making the decision-making process fully transparent and well followed. All other quantification values (QV) are evaluated in respect to QSV.

\subsubsection{Attribute 1: Maintenance History}

One of the useful indicators about the actual performance of the infrastructure is information on the frequency and extent of past maintenance. For embankments, the main regular intervention performed is ballast tamping, while ballast cleaning or renewal interventions are performed occasionally [11]. In this work, the frequency of tampering activities is taken into account as the relevant attribute. From the whole data set, a maximum number $\left(f_{\max , t / y, i}\right)$ of tampering per year is assigned a quantification starting value (QSV) of 1 , while the no-tampering events per year get the quantification value 0 . Intermediate values are calculated as follows:

$$
\mathrm{QV}_{\mathrm{C} 1, \mathrm{i}}=\frac{\mathrm{f}_{\mathrm{t} / \mathrm{y}, \mathrm{i}}}{\mathrm{f}_{\mathrm{max}, \mathrm{t} / \mathrm{y}, \mathrm{i}}}
$$

where $\mathrm{C} 1$ represents Attribute $1, \mathrm{QVC}_{1}$ represents the quantification value of Attribute 1 , and $\mathrm{f}_{\mathrm{t} / \mathrm{y}, \mathrm{i}}$ represents the tampering frequency per year for an observed section of a railway line, while $f_{\text {max }, t / y, i}$ represents the tampering frequency per year for the most tampered section along the investigated railway line. 


\subsubsection{Attribute 2: Visual Assessment of External Irregularities}

Visual inspections of railway embankments are performed by experienced engineers, with the overall aim of recording visible irregularities along the line. The engineers' remarks about the observed irregularities, as well as detailed photo-documentation, are used to define Attribute 2. It has to be noted that it is very challenging to quantify the irregularities due to their different nature and impact on the overall embankment condition as well as their extent. For example, a logical question could be, would a section with two small landslides observed have a higher QV value than a section with a single larger landslide? To overcome these issues, a percentage of length of irregularity extent in comparison to total section length is defined as the relevant quantifiable attribute. The following irregularities should be considered:

- Observable embankment slope slips (material failure in the side slope);

- Observable embankment bulging (evidence of the slide slopes expanding laterally);

- Observable crest settlement (suggesting settlement of the material beneath the embankment);

- Broken sleepers.

From the whole data set, the maximum number of irregularities $\left(\mathrm{V}_{\max , \mathrm{RI}, \mathrm{i}}\right)$ per section is assigned a quantification starting value (QSV) of 1 , while 'no visible irregularities' is assigned a value 0 . The rest are calculated as follows:

$$
\mathrm{QV}_{\mathrm{C} 2, \mathrm{i}}=\frac{\mathrm{V}_{\mathrm{IR}, \mathrm{i}}}{\mathrm{V}_{\mathrm{max}, \mathrm{IR}, \mathrm{i}}}
$$

where $C_{2}$ represents Attribute 2, $Q V_{C 2}$ represents the quantification value of Attribute 2, and $V_{I R, i}$ represents the number of visually determined irregularities for an observed section of a railway line, while $V_{\text {max,IR,i }}$ represents the number of visually determined irregularities for the section with the most irregularities along the investigated railway line.

\subsubsection{Attributes 3-5: A GPR Investigation Data}

To obtain GPR data relevant for the proposed methodology, a multi-antenna set-up should be implemented. The reason for this is that higher frequency antennas emit electromagnetic waves with a shorter pulse wavelength, therefore enabling the detection of smaller features and providing a high-resolution profile of the ballast bottom and data for analysis of ballast fouling. On the other hand, lower frequency antennas are used to locate potential anomalies in the sub-ballast and embankment fill. The investigation set-up should include both ground-coupled/lower frequency and air-coupled/higher frequency units. A high-frequency antenna (at least $1 \mathrm{GHz}$ ) is used to investigate shallow features such as ballast pockets and ballast quality (fouling), which represent Attribute 3 and Attribute 4, respectively. Lower frequency antennas, for example up to $400 \mathrm{MHz}$ (depending on the height of the investigated embankment), should be used to map deep irregularities within the sub-ballast and embankment material, labeled as Attribute 5.

Attribute 3: The Depth of Ballast Layer (Ballast Pockets)

When a ballast penetrates into the lower layers, a depression beneath the ballast layer is formed and referred to as the 'ballast pocket' (Figure 1). Usually, the formation of ballast pockets occurs together with fouling, since during penetration fine grained material intermixes with the clean ballast. When the GPR trace propagates through the clean ballast layer, significant signal scattering occurs, leading to higher signal amplitudes (Figure 1a). Within the sub-ballast layer, the signal is attenuated. By combining the phase and manual layer pick method, the contact between the ballast layer and sub-ballast layer can be determined in a semi-automatic manner. During the determination of the ballast depth, it is important to properly evaluate the value of the dielectric constant of the ballast, since this value affects the depth of the ballast bottom. After the ballast bottom has been marked on the radargram by manual and phase picking (Figure 1b), the depth of the ballast bottom can be easily 
obtained. Results are extracted in the form of a report containing information on trace number, profile distance, trace amplitude, two-way travel time, and depth to the ballast layer bottom.

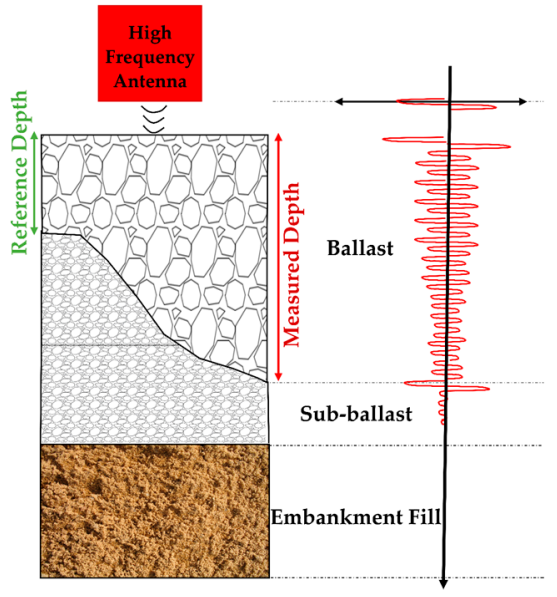

(a)

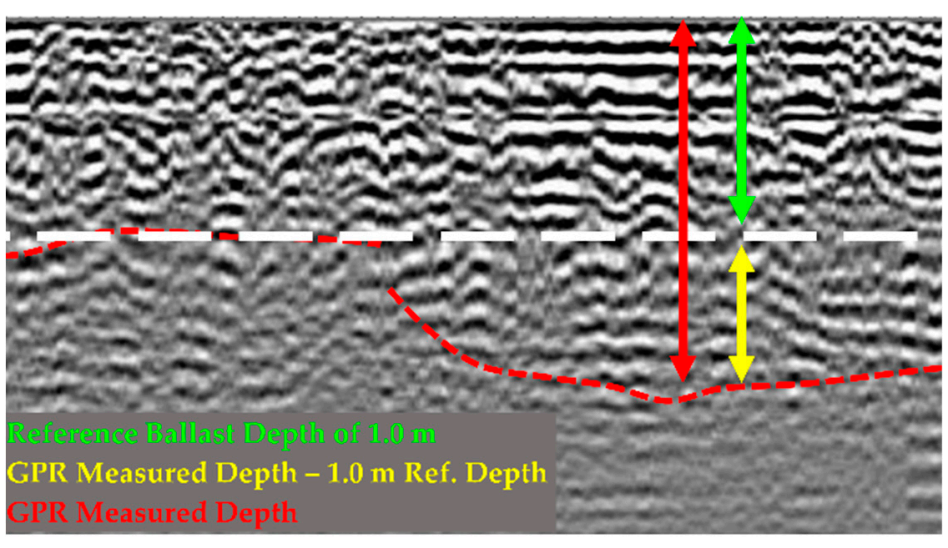

(b)

Figure 1. Determination of ballast pockets: (a) Ground Penetrating Radar trace in case of ballast pocket formation and (b) radagram showing the features for the determination of Attribute 3.

On the Croatian network, the normal ballast depth is $0.5 \mathrm{~m}(0.30 \mathrm{~m}$ below the sleeper bottom, with the addition of sleeper thickness, since the reference investigation surface is top of the sleeper). Therefore, Attribute 3 is defined as the measured thickness of a ballast layer in excess of $0.5 \mathrm{~m}$. If the measured ballast depth is $0.5 \mathrm{~m}$, there is no ballast pocket present. The overall steps for the determination of the ballast depth for a provisional $100 \mathrm{~m}$ long section of a railway line are shown in Table 1. It is recommended to utilize signal trace separation of maximum $5 \mathrm{~cm}$, leading to $20 \mathrm{traces} / \mathrm{m}$ of the investigated line, in order to have a better insight into the position of the layer bottom. The results can be evaluated on each $1 \mathrm{~m}$ of the investigated line, that is for every 20th signal trace. After determination of measured depth for each trace, an averaging procedure for the whole investigated section follows.

Table 1. Methodology steps for the determination of ballast layer depth.

\begin{tabular}{|c|c|c|c|c|c|}
\hline Trace Number & $\begin{array}{l}\text { Investigation } \\
\text { Distance (m) }\end{array}$ & $\begin{array}{l}\text { Measured } \\
\text { Depth (m) }\end{array}$ & $\begin{array}{l}\text { Average Measured } \\
\text { Depth (m) }\end{array}$ & $\Delta \mathrm{d}_{\mathrm{i}}(\mathrm{m})$ & $\mathrm{QV}_{\mathrm{C} 3, \mathrm{i}}(-)$ \\
\hline 1 (1st overall) & 0.0 & $\mathrm{~d}_{\text {measured }, 0}$ & \multirow{5}{*}{$\frac{\sum \mathrm{d}_{\text {measured }, \mathrm{i}}}{100}$} & \multirow{5}{*}{$\frac{\sum \mathrm{d}_{\text {measured, }}}{100}-$} & \multirow{5}{*}{$\frac{\Delta \mathrm{d}_{\mathrm{i}}}{\Delta \mathrm{d}_{\max , \mathrm{i}}}$} \\
\hline 2 (21st overall) & 1.0 & $\mathrm{~d}_{\text {measured,1 }}$ & & & \\
\hline 3 (41st overall) & 2.0 & $\mathrm{~d}_{\text {measured,2 }}$ & & & \\
\hline$\cdots$ & $\cdots$ & $\cdots$ & & & \\
\hline $\begin{array}{c}100 \text { (2001st } \\
\text { overall) }\end{array}$ & 100.0 & $d_{\text {measured, } 100}$ & & & \\
\hline
\end{tabular}

$\Delta \mathrm{d}_{\text {max, } \mathrm{i}}$ is determined by the same methodology as given in Table 1 , and it represents the line section with the highest average measure depth $\left(\frac{\sum \mathrm{d}_{\text {measured,max,i }}}{100}-0.5 \mathrm{~m}\right)$. From the data used to formulate the approach, the maximum ballast layer depth measured is assigned a quantification starting value (QSV) of 1, while a ballast layer of $0.5 \mathrm{~m}$ is assigned a value 0 . The rest are calculated as follows:

$$
\mathrm{QV}_{\mathrm{C} 3, \mathrm{i}}=\frac{\Delta \mathrm{d}_{\mathrm{i}}}{\Delta \mathrm{d}_{\max , \mathrm{i}}}
$$


where $C_{3}$ represents Attribute $3, Q V_{C 3}$ represents the quantification value of Attribute 3 , and $\Delta d_{i}$ represents the measured value of ballast depth minus the designed depth of $0.5 \mathrm{~m}$ for an observed section of a railway line, while $\Delta \mathrm{d}_{\text {max,i }}$ represents the maximum measured value of ballast depth minus the designed depth of $0.5 \mathrm{~m}$ for the section with measured maximum ballast depth along the investigated railway line.

Attribute 4: Ballast Fouling (Quality of Ballast Layer)

High-frequency antennas are also used for the determination of ballast fouling. Ballast fouling is a direct consequence of the ballast aging process, where fine-grained materials fill the ballast void spaces, leading to track instability with serious implications on track drainage [32]. Even though GPR is commonly used for the inspection of ballast fouling, Panjamani et al. [10] state that there are no robust guidelines to find the degree and type of fouling quantitatively. A good quality, clean ballast is approximately of $30-60 \mathrm{~mm}$ size and should be dry. Therefore, GPR signal scattering should be prominent as shown in Figure 1a. However, if the layer is infiltrated with fine-grained materials and consequently with water, more attenuation could be expected (Figure 2a). A fouled ballast does not scatter emitted energy so much, since the air gaps are now filled with smaller grain materials. This principle is widely accepted as a good way to assess the degree of ballast fouling [33]. An example of a clean ballast zone and a fouled ballast zone is given on the radargram in Figure $2 \mathrm{~b}$.

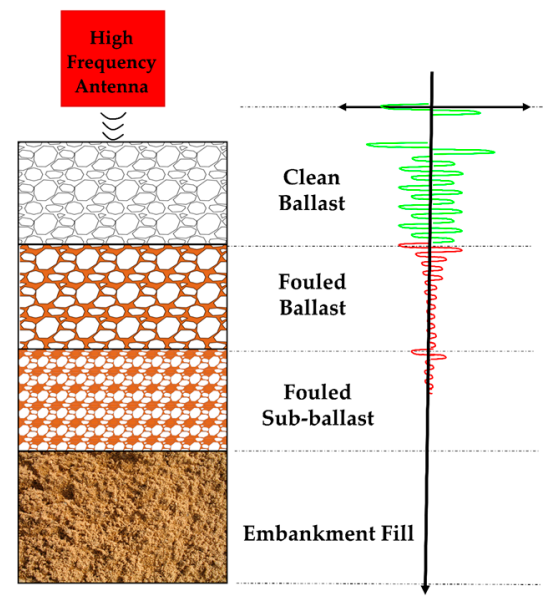

(a)

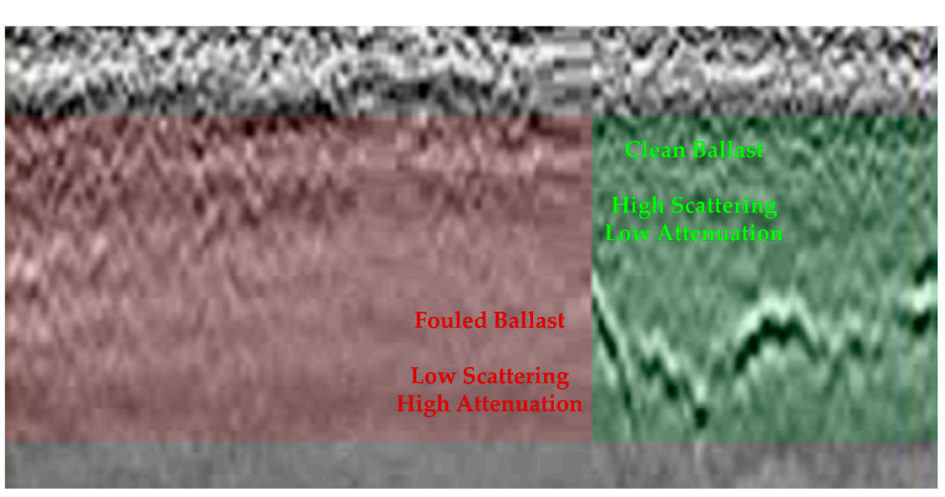

(b)

Figure 2. Determination of ballast fouling: (a) Ground Penetrating Radar trace in case of ballast fouling and $(\mathbf{b})$ radagram showing the difference between clean and fouled ballasts.

After basic processing, each GPR trace is extracted from the radargram and subjected to further analysis by using a MATLAB developed code. Several steps are conducted in order to determine a quantifiable value for Attribute 4, relevant for each section of a line. As a first step, a trace is divided into several depth zones, each with a pre-defined depth of $10 \mathrm{~cm}$. The total number of zones $\left(\mathrm{k}_{\max }\right)$ depends on the overall position of the ballast layer bottom. Next, the maximum amplitude of each depth zone is determined, where an amplitude envelope is constructed by connecting the peaks of the reflections down a trace (Figure 3). 


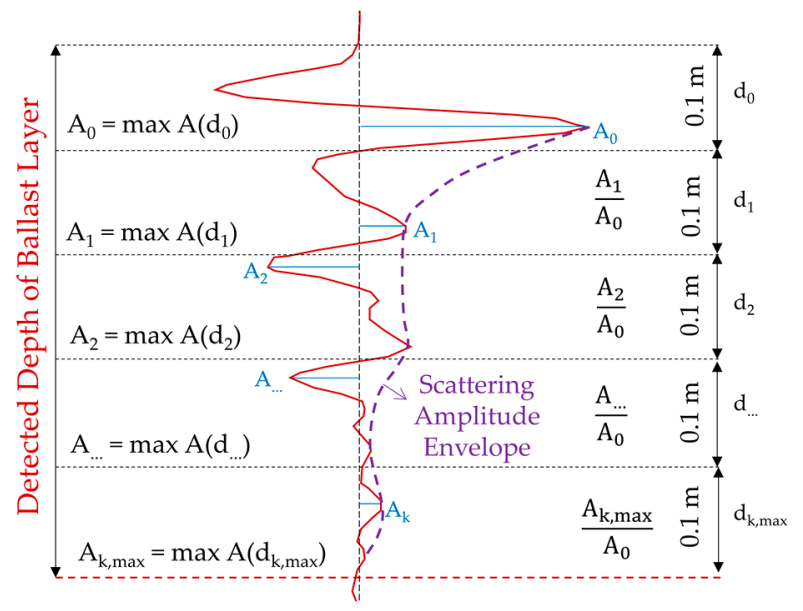

Figure 3. Elements of a single Ground Penetrating Radar trace for the determination of ballast fouling.

A lower amplitude value could be associated with a fouled ballast. After determining the amplitude ratio $A_{i} / A_{0}$ for each depth zone, an averaging procedure for the whole trace is conducted with the determination of an average amplitude decrease (AAD) ratio for a single trace. From there, ballast fouling (\%) is determined for a single trace, followed by the calculation of average ballast fouling for the whole investigated section. The overall steps for the determination of a ballast fouling percentage for a provisional $100 \mathrm{~m}$ long section of railway line are shown in Table 2. It is recommended to utilize signal trace separation of maximum $5 \mathrm{~cm}$ (horizontal resolution), leading to 20 traces $/ \mathrm{m}$ of the investigated line, with each trace divided into at least 512 samples (vertical resolution). For the ballast fouling evaluation, each signal trace should be analyzed.

Table 2. Methodology steps for the determination of ballast fouling.

\begin{tabular}{|c|c|c|c|c|c|}
\hline Trace Number & $\begin{array}{c}\text { Investig. } \\
\text { Distance (m) }\end{array}$ & $\begin{array}{l}\text { Average Amplitude } \\
\text { Decrease AAD (-) }\end{array}$ & $\begin{array}{c}\text { Signal Attenuation, } \\
\text { i.e., Ballast Fouling (BQ) (-) }\end{array}$ & $\begin{array}{c}\text { BQ Average } \times \\
100(\%)\end{array}$ & $\mathrm{QV}_{\mathrm{C} 4, \mathrm{i}}(-)$ \\
\hline 1 (1st overall) & 0.0 & $\begin{array}{c}\mathrm{AAD}_{\mathrm{n}}= \\
\left(\frac{\sum_{\mathrm{k}=0}^{\mathrm{k}_{\max }}\left(\frac{A_{\mathrm{k}}}{\mathrm{A}_{0}}\right)}{\mathrm{k}_{\max }}\right)\end{array}$ & $(B Q)_{1}=1-\mathrm{AAD}_{1}$ & & \\
\hline 1 (2nd overall) & 0.05 & 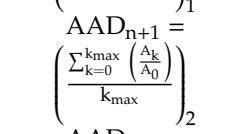 & $(B Q)_{2}=1-A_{A D}$ & $\mathrm{BQ}_{\mathrm{i}}=\frac{\sum \mathrm{BQ}}{2001}$ & $\frac{\mathrm{BQ}_{\mathrm{i}}}{\mathrm{BQ}_{\max , \mathrm{i}}}$ \\
\hline $2(3 r d$ overall $)$ & 0.10 & $\left.\frac{\left(\sum_{\mathrm{k}=0}^{\mathrm{k}_{\max }}\left(\frac{\mathrm{A}_{\mathrm{k}}}{\mathrm{A}_{0}}\right)\right.}{\mathrm{k}_{\max }}\right)_{3}$ & $(B Q)_{3}=1-\mathrm{AAD}_{3}$ & & \\
\hline 3 (4th overall) & 0.15 & 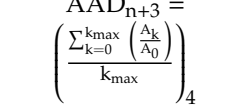 & $(B Q)_{4}=1-\mathrm{AAD}_{4}$ & & \\
\hline $\begin{array}{c}\ldots \\
2001(2001 s t \\
\text { overall) }\end{array}$ & 100.0 & $\begin{array}{c}\cdots \\
\left(\frac{\sum_{\mathrm{k}=0}^{\mathrm{k}_{\max }\left(\frac{A_{\mathrm{k}}}{\mathrm{A}_{0}}\right)}}{\mathrm{k}_{\max }}\right)_{2001}\end{array}$ & $(B Q)_{2001}=1-A_{A D} 2001$ & & \\
\hline
\end{tabular}

$\mathrm{BQ}_{\max , \mathrm{i}}$ is determined by the same methodology as given in Table 2, and it represents the line section with the highest average fouling percentage. A non-fouled ballast (clean-ballast) has a $0 \%$ fouling degree (QSV of 0). A QSV of 1 is attributed to the section with highest fouling degree, while the rest are calculated as follows:

$$
\mathrm{QV}_{\mathrm{C} 4, \mathrm{i}}=\frac{\mathrm{BQ}_{\mathrm{i}}}{\mathrm{BQ}_{\max , \mathrm{i}}}
$$

where $\mathrm{C}_{4}$ represents Attribute $4, \mathrm{QV}_{\mathrm{C} 4}$ represents the quantification value of Attribute 4 , and $\mathrm{BQ}_{\mathrm{i}}$ represents the value of ballast fouling (in \%) for an observed section of a railway line, while $B Q_{\max , i}$ 
represents the value of ballast fouling for the section with the lowest quality/maximum fouling of ballast along the investigated railway line.

\section{Attribute 5: Irregularities in Sub-Ballast and Embankment Fill}

Although Selig and Waters [34] note that degradation mostly affects the ballast layer, it is important to map and detect defects in the sub-ballast and subgrade layers. In this case, lower frequency antennas are used to locate anomalies in the sub-ballast and embankment fill (voids, animal burrows, water erosion channels, etc.). Reflections of the emitted waves occur when the signal reaches boundaries and/or anomalies at larger depths. The presence of irregularities results in specific signal trace peaks (Figure 4a). If the anomaly is in the form of a void within the investigated layers, for example, animal burrows, it shows in the radargram in the form of a hyperbola (Figure $4 \mathrm{~b}$ ). The parameters of these hyperbolas are commonly determined by utilization of generalized Hough transform or, recently, by utilization of neural network tools to reduce the analysis time [35].

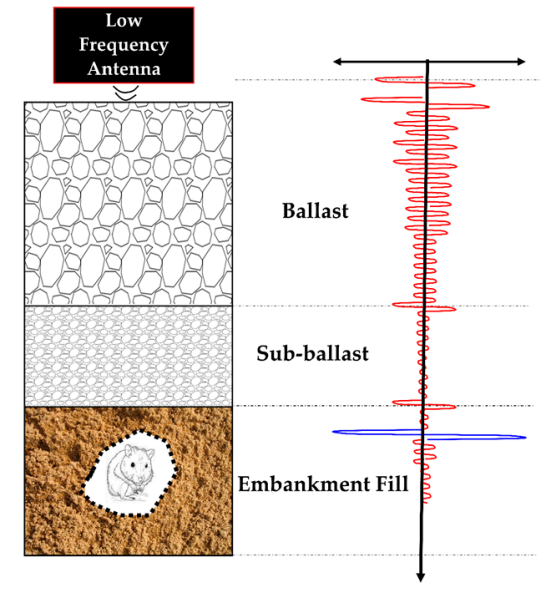

(a)

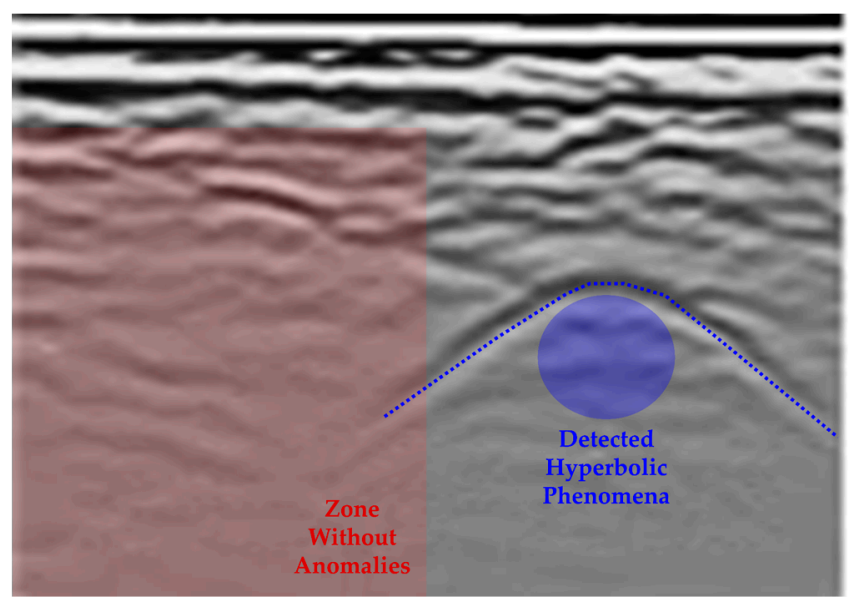

(b)

Figure 4. Determination of deeper irregularities: (a) Ground Penetrating Radar trace in case of deep irregularity presence and (b) radagram showing the detected hyperbolic phenomena.

From the whole data set, the maximum number of deep irregularities $\left(\mathrm{D}_{\max , I R, i}\right)$ per section is assigned a quantification starting value (QSV) of 1 , while 'no deep irregularities' is assigned a value 0 . The rest are calculated as follows:

$$
\mathrm{QV}_{\mathrm{C} 5, \mathrm{i}}=\frac{\mathrm{D}_{\mathrm{IR}, \mathrm{i}}}{\mathrm{D}_{\max , \mathrm{IR}, \mathrm{i}}},
$$

where $C_{5}$ represents Attribute $5, Q_{C 5}$ represents the quantification value of Attribute 5 , and $D_{I R, 1}$ represents the number of deep irregularities for an observed section of a railway line, while $D_{\max , I R, i}$ represents the number of deep irregularities for the section with the maximum number of irregularities along the investigated railway line. These values are determined based on a visual assessment of each radargram, by counting the number of hyperbolic phenomena for each investigated section.

\subsection{Implementation of Multi-Attribute Utility Theory}

To effectively implement MAUT into a methodology for railway embankment condition assessment, several steps need to be considered. A detailed description of the mathematical basis of the MAUT approach is presented in [36-38]. After the selection and determination of the quantification values of the attributes $\left(\mathrm{QV}_{C}\right)$ using Equations (1)-(5), the following step includes calculation of the utility function values for the selected ' $n$ ' number of attributes (five attributes are proposed in the paper) and ' $m$ ' number of alternatives. An alternative (S) is defined as 'a sub-section of pre-defined 
length'. In this case, $100 \mathrm{~m}$ long sub-sections were considered, which determine the resolution for categorization. Any other resolution length, adapted to the character of specific problem and to the needs of infrastructure managers, can also be considered.

The overall MAUT problem can be expressed by an $m \times n$ decisional matrix, having the form as shown in Table 3.

Table 3. The Multi Attribute Utility Theory matrix for railway embankment condition assessment.

\begin{tabular}{ccccccc}
\hline & $\begin{array}{r}\text { Attribute } \\
\mathbf{Q V}(\mathbf{n})\end{array}$ & $\mathbf{Q V}_{\mathbf{C} 1}$ & $\mathbf{Q V}_{\mathrm{C} 2}$ & $\mathbf{Q V}_{\mathrm{C} 3}$ & $\mathbf{Q V}_{\mathbf{C} 4}$ & $\mathbf{Q V}_{\mathbf{C} 5}$ \\
Alternatives (m) & & $\overline{\mathrm{U}_{1}}\left(\mathrm{~S}_{1}\right)$ & $\overline{\mathrm{U}_{2}}\left(\mathrm{~S}_{1}\right)$ & $\overline{\mathrm{U}_{3}}\left(\mathrm{~S}_{1}\right)$ & $\overline{\mathrm{U}_{4}}\left(\mathrm{~S}_{1}\right)$ & $\overline{\mathrm{U}_{5}}\left(\mathrm{~S}_{1}\right)$ \\
\hline $\mathrm{S}_{1}$ & & $\overline{\mathrm{U}_{1}}\left(\mathrm{~S}_{2}\right)$ & $\overline{\mathrm{U}_{2}}\left(\mathrm{~S}_{2}\right)$ & $\overline{\mathrm{U}_{3}}\left(\mathrm{~S}_{2}\right)$ & $\overline{\mathrm{U}_{4}}\left(\mathrm{~S}_{2}\right)$ & $\overline{\mathrm{U}_{5}}\left(\mathrm{~S}_{2}\right)$ \\
$\mathrm{S}_{2}$ & & $\overline{\mathrm{U}_{1}}\left(\mathrm{~S}_{\mathrm{m}}\right)$ & $\overline{\mathrm{U}_{2}}\left(\mathrm{~S}_{\mathrm{m}}\right)$ & $\overline{\mathrm{U}_{3}}\left(\mathrm{~S}_{\mathrm{m}}\right)$ & $\overline{\mathrm{U}_{4}}\left(\mathrm{~S}_{\mathrm{m}}\right)$ & $\overline{\mathrm{U}_{5}}\left(\mathrm{~S}_{\mathrm{m}}\right)$ \\
\hline
\end{tabular}

The normalized utility function values can be determined using the following equation:

$$
\overline{\mathrm{U}_{\mathrm{i}}}\left(\mathrm{S}_{\mathrm{j}}\right)=\frac{\mathrm{QV}_{\mathrm{C}, \mathrm{i}}\left(\mathrm{S}_{\mathrm{j}}\right)}{\sum_{\mathrm{j}=1}^{\mathrm{m}} \mathrm{QV}_{\mathrm{C}, \mathrm{i}}\left(\mathrm{S}_{\mathrm{j}}\right)},
$$

where

$\overline{\mathrm{U}_{\mathrm{i}}}\left(\mathrm{S}_{\mathrm{j}}\right)$-normalized utility function value for Attribute $i$ and Alternative $j$

$\mathrm{S}_{\mathrm{j}}$-Alternative $j$, subsection of $100 \mathrm{~m}$ in length; $\mathrm{j}=1,2, \ldots, \mathrm{m}$

$m$-number of alternatives

$\mathrm{QV}_{\mathrm{C}, \mathrm{i}}$-quantification value of Attribute $i ; \mathrm{i}=1,2, \ldots, \mathrm{n}$

$n$-number of attributes

The sum of all utility function values for a specific alternative is equal to 1 :

$$
\sum_{\mathrm{i}=1}^{\mathrm{n}} \overline{\mathrm{U}_{\mathrm{i}}}\left(\mathrm{S}_{\mathrm{j}}\right)=1 .
$$

The next step in the implementation of MAUT includes the evaluation of the importance of each selected attribute. To do this, a grading scheme is established, where the grading of importance of each attribute for the embankment condition assessment is conducted by attributing a grade ranging from 1 (negligible importance) to 10 (extremely important). This information was collected using a questionnaire completed by experienced engineers working in the field of infrastructure management. The determination of each attribute's importance is thus by nature subjective, reflecting the experience and risk acceptance of the engineers in question. After determining mean values and standard deviations of the assigned grades, a weight of importance for a specific attribute can be calculated by:

$$
\mathrm{w}_{\mathrm{i}}=\frac{\mathrm{QV}_{\mathrm{C}, \mathrm{i}}}{\sum_{\mathrm{i}=1}^{\mathrm{n}} \mathrm{QV}_{\mathrm{C}, \mathrm{i}}}
$$

where

$\mathrm{w}_{\mathrm{i}}$-weight of importance for Attribute $i$

The sum of all weight values for all attributes is equal to 1 :

$$
\sum_{i=1}^{n} w_{i}=1 .
$$


Finally, the overall utility function values $\mathrm{U}\left(\mathrm{S}_{\mathrm{j}}\right)$ for each alternative are calculated by combining the calculated utility functions (Equation (6)) and the weight of importance (Equation (8)):

$$
\mathrm{U}\left(\mathrm{S}_{\mathrm{j}}\right)=\sum_{\mathrm{i}=1}^{\mathrm{n}} \mathrm{w}_{\mathrm{i}} \cdot \overline{\mathrm{U}_{\mathrm{i}}}\left(\mathrm{S}_{\mathrm{j}}\right),
$$

where

$\mathrm{U}\left(\mathrm{S}_{\mathrm{j}}\right)$ - the overall utility function value for Alternative $j$

After the overall utility function is calculated for each alternative, the development of a final ranking list is completed as follows. A classification list is developed for five (5) categories ranging from an embankment in a very poor to very good condition. The appropriate MAUT condition for each category is shown in Table 4 . The list is color-coded in order to be easily comprehensible for railway infrastructure managers.

Table 4. Categorization representation with Multi Attribute Utility Theory conditions.

\begin{tabular}{|c|c|c|c|}
\hline Category & Condition & $\begin{array}{c}\text { Graphical } \\
\text { Representation }\end{array}$ & MAUT Condition \\
\hline 1 & Very poor & & $0.8<\mathrm{U}\left(\mathrm{S}_{\mathrm{j}}\right) \leq 1.0$ \\
\hline 2 & Poor & & $0.6<\mathrm{U}\left(\mathrm{S}_{\mathrm{j}}\right) \leq 0.8$ \\
\hline 3 & Adequate & & $0.4<\mathrm{U}\left(\mathrm{S}_{\mathrm{j}}\right) \leq 0.6$ \\
\hline 4 & Good & & $0.2<\mathrm{U}\left(\mathrm{S}_{\mathrm{j}}\right) \leq 0.4$ \\
\hline 5 & Very good & & $0.0<\mathrm{U}\left(\mathrm{S}_{\mathrm{j}}\right) \leq 0.2$ \\
\hline
\end{tabular}

A higher value of overall utility function for a specific alternative reflects a larger number of visible as well as deeper (GPR) anomalies, larger ballast depth, lower ballast quality, and more tampering activities per year.

\section{Case Study Example}

\subsection{Description of the Case Study Area}

The railway network in Croatia consists of more than $2600 \mathrm{~km}$ of lines, with the majority forming parts of European railway transport corridors (Figure 5). Given the general age of the railway infrastructure and deterioration including the impact of war conflicts [39], a number of sections have traffic speed restrictions with maximum speeds of only $20 \mathrm{~km} / \mathrm{h}$ on some sections.

To validate the categorization procedure proposed in this paper, a case study was chosen which included $181 \mathrm{~km}$ of railway embankments in Croatia along 18 different railway lines. For each investigated line, a categorization procedure was conducted. The investigated lines were chosen by railway managers from eight Supervision Centers (SC) of the Croatian Railway Infrastructure: SC Ogulin (three investigated lines), SC Osijek (three investigated lines), SC Pula (one investigated line), SC Rijeka (one investigated line), SC Slavonski Brod (two investigated lines), SC Varaždin (four investigated lines), SC Vinkovci (one investigated line), and SC Zagreb (three investigated lines). 


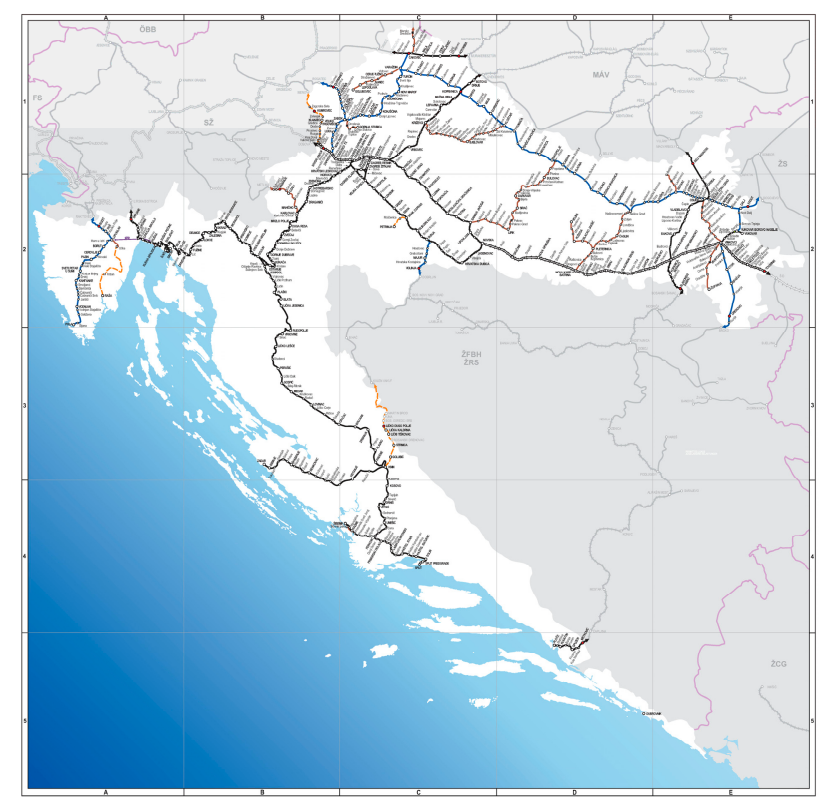

Figure 5. Railway network in Croatia, scale 1:6,000,000, from [40].

\subsection{Data Acquisition Procedure}

As a starting point in the categorization procedure, each SC provided information on the tamping frequency for the railway lines under their supervision. The tamping activities are usually determined solely on the basis of visual assessment and periodical measurements of the track level. In the study area, the tamping frequency was provided for the year prior to the in-situ assessment which followed.

The next step included expert visual assessment of the sections and the performance of ground-penetrating radar (GPR) investigations. The visual assessment included walking along the selected line sections and recording of detailed photos and video-documentation along with textual description of each phenomena, including its shape, extent, and the potential nature of the irregularity. The assessment was done by a multidisciplinary team consisting of railway inspectors, geotechnical engineers, and geologists.

The GPR investigation methodology included a multi-channel approach in order to detect the phenomena which are defined as attributes for methodology of embankment categorization (Figure 6). For the purpose of distance measurements during data acquisition, a distance measuring instrument (DMI) was attached to the survey wheel of a specially constructed bogey which housed the GPR equipment. In this study, the signal trace separation was $5 \mathrm{~cm}$, leading to 20 traces per $\mathrm{m}$ of investigated track. The rapid nature of GPR testing was essential, since the investigations were conducted during the day with minimal line closure as requested by infrastructure managers. 


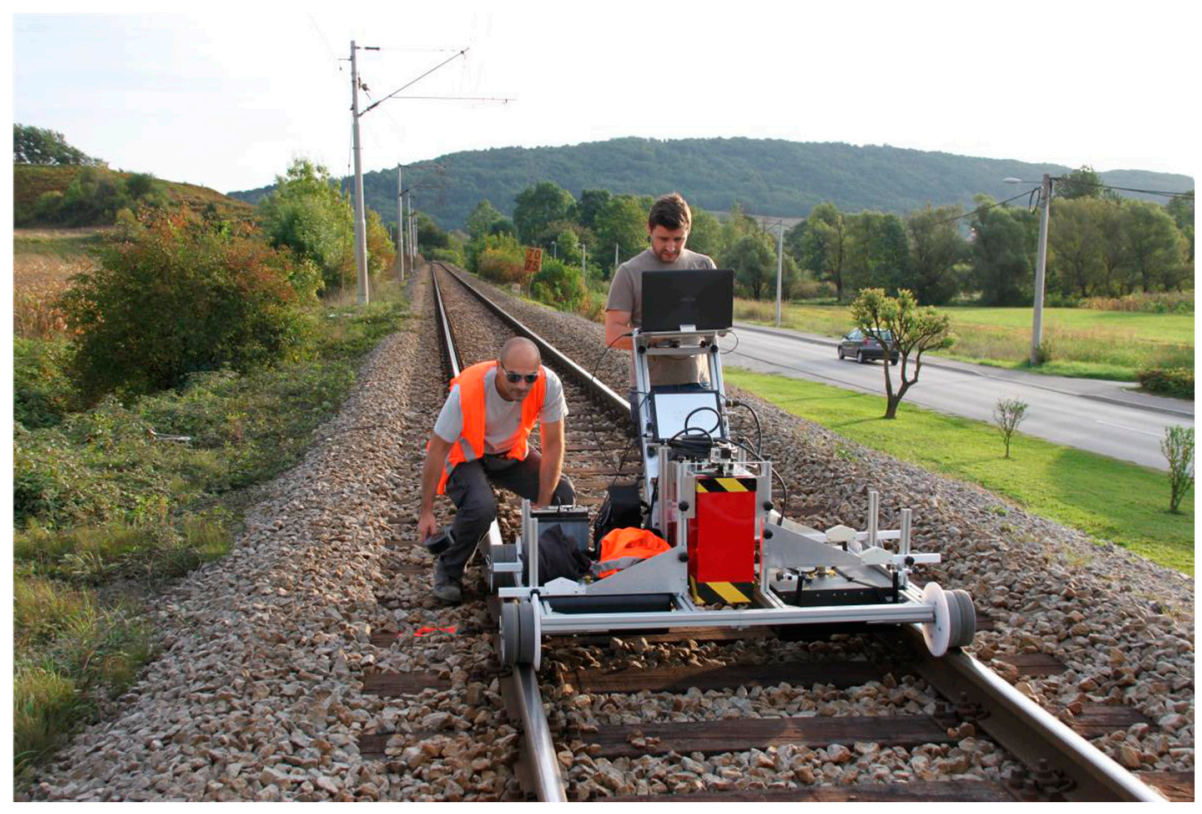

Figure 6. Conduction of GPR investigations.

\subsection{Results and Discussion}

The terminology used in this section includes the following terms: 'line' as the railway line, 'section' as part of the line under investigation, and 'subsection' is a $100 \mathrm{~m}$ length of the investigated line. Therefore, for the total of $181.1 \mathrm{~km}$ of 18 investigated sections on 18 different railway lines, we had 1811 subsections, which were analyzed and represented the alternatives for the implemented multi-attribute utility theory model. Taking into consideration that sections selected for investigation were part of different lines, the analysis for 18 sections were done independently, bearing in mind that maintenance on those sections would also be performed independently. Sections differed from $1.0 \mathrm{~km}$ of length, which had 10 alternatives (10 subsections of $100 \mathrm{~m}$ length) to the largest one, which was $31.3 \mathrm{~km}$ long and consisted of 313 alternatives. This division was done in agreement with the Supervision Centers, since it was rational to separately evaluate these groups, rather than implementing categorization procedure for all the lines together. The division will enable infrastructure managers' better insight into the condition of each section within the relevant line, where a subsequent resource optimization can be conducted.

As a first step in implementing the developed methodology in the case study, attributes were evaluated for all alternatives within each section. The quantification values were determined as given by Equations (1)-(5). An example of attribute evaluation is given for a $1000 \mathrm{~m}$ long section, divided into $100 \mathrm{~m}$ subsections, in Table 5 .

Next, a multi-attribute decision-making problem was expressed by an $n \times m$ decisional matrix, $n$ being the number of attributes ( 5 in our case) and $m$ being the number of alternatives within one section. Considering the 18 investigated lines, the alternatives were divided into 18 groups $(k=1$, $2, \ldots, 18)$, leading to the formation of $18 n \times m$ decisional matrices, the smallest one being $5 \times 10$ and the largest one being $5 \times 313$. As a first step in calculating the overall utility function of each alternative $\mathrm{U}_{\mathrm{i}}\left(\mathrm{S}_{\mathrm{j}}^{\mathrm{k}}\right)$, the normalized utility functions were determined using Equation (6). For example, the normalized utility function value for the GPR fouling Attribute $\left(\mathrm{QV}_{\mathrm{C}}\right)$ and Alternative $\left(\mathrm{S}_{5}^{1}\right)$ which stands for 'fifth alternative within the first section' was calculated as:

$$
\overline{\mathrm{U}_{4}}\left(\mathrm{~S}_{5}^{1}\right)=\frac{\mathrm{QV}_{\mathrm{C} 4}\left(\mathrm{~S}_{5}^{1}\right)}{\sum_{\mathrm{j}=1}^{\mathrm{m}} \mathrm{QV}_{\mathrm{C} 4}\left(\mathrm{~S}_{\mathrm{j}}^{1}\right)}
$$


with

$$
\sum_{\mathrm{i}=1}^{5} \overline{\mathrm{U}_{\mathrm{i}}}\left(\mathrm{S}_{5}^{1}\right)=1 .
$$

Further, to define the importance of each of the five attributes in the overall embankment categorization procedure, a developed questionnaire was used to obtain information from experienced experts working in the railway maintenance sector. To overcome the mentioned subjectivity aspect, a questionnaire was delivered to 12 experts, and the results are given in Table 6.

Table 5. An example of attribute evaluation from one of the sections.

\begin{tabular}{|c|c|c|c|c|c|c|c|c|c|c|}
\hline \multirow{2}{*}{ Alternative } & 1 & 2 & 3 & 4 & 5 & 6 & 7 & 8 & 9 & 10 \\
\hline & $\begin{array}{c}\mathrm{km} \\
0.0-0.1\end{array}$ & $\begin{array}{c}\mathrm{km} \\
0.1-0.2 \\
\end{array}$ & $\begin{array}{c}\mathrm{km} \\
0.2-0.3\end{array}$ & $\begin{array}{c}\mathrm{km} \\
0.3-0.4\end{array}$ & $\begin{array}{c}\mathrm{km} \\
0.4-0.5\end{array}$ & $\begin{array}{c}\mathrm{km} \\
0.5-0.6\end{array}$ & $\begin{array}{c}\mathrm{km} \\
0.6-0.7\end{array}$ & $\begin{array}{c}\mathrm{km} \\
0.7-0.8\end{array}$ & $\begin{array}{c}\mathrm{km} \\
0.8-0.9\end{array}$ & $\begin{array}{c}\mathrm{km} \\
0.9-1.0\end{array}$ \\
\hline Tampering per year & 3 & 0 & 0 & 5 & 2 & 3 & 3 & 4 & 2 & 2 \\
\hline $\mathrm{QV}_{\mathrm{C} 1}$ & 0.60 & 0.00 & 0.00 & $\begin{array}{c}1.00 \\
\left(\mathrm{QSV}_{\mathrm{C} 1}\right)\end{array}$ & 0.40 & 0.60 & 0.60 & 0.80 & 0.40 & 0.40 \\
\hline $\begin{array}{c}\% \text { of visual irregularities } \\
\text { per section }\end{array}$ & 10 & 0 & 5 & 70 & 90 & 40 & 40 & 50 & 50 & 40 \\
\hline $\mathrm{QV}_{\mathrm{C} 2}$ & 0.11 & 0.00 & 0.56 & 0.77 & $\begin{array}{c}1.00 \\
\left(\mathrm{QSV}_{\mathrm{C} 2}\right)\end{array}$ & 0.44 & 0.44 & 0.56 & 0.56 & 0.44 \\
\hline average depth (m) & 1.32 & 1.25 & 1.29 & 1.34 & 1.36 & 1.17 & 1.23 & 1.09 & 1.05 & 1.06 \\
\hline $\mathrm{QV}_{\mathrm{C} 3}$ & 0.95 & 0.87 & 0.92 & 0.98 & $\begin{array}{l}1.00 \\
\left(\mathrm{QSV}_{\mathrm{C} 3}\right)\end{array}$ & 0.78 & 0.84 & 0.69 & 0.64 & 0.65 \\
\hline fouled $\%$ per section & 40 & 10 & 50 & 80 & 60 & 20 & 20 & 30 & 30 & 40 \\
\hline $\mathrm{QV}_{\mathrm{C} 4}$ & 0.50 & 0.13 & 0.63 & $\begin{array}{l}1.00 \\
\left(\mathrm{QSV}_{\mathrm{C} 4}\right)\end{array}$ & 0.75 & 0.25 & 0.25 & 0.38 & 0.38 & 0.50 \\
\hline $\begin{array}{l}\text { GPR irregularities per } \\
\text { section }\end{array}$ & 0 & 1 & 2 & 4 & 0 & 0 & 2 & 4 & 0 & 0 \\
\hline $\mathrm{QV}_{\mathrm{C5}}$ & 0.00 & 0.25 & 0.50 & $\begin{array}{c}1.00 \\
\left(\mathrm{QSV}_{\mathrm{C} 5}\right)\end{array}$ & 0.00 & 0.00 & 0.50 & $\begin{array}{c}1.00 \\
\left(\mathrm{QSV}_{\mathrm{C} 5}\right)\end{array}$ & 0.00 & 0.00 \\
\hline
\end{tabular}

Table 6. Mean values, standard deviations, and calculated weight of importance for attributes.

\begin{tabular}{ccccc}
\hline Attribute & Label & Mean & SD & $\begin{array}{c}\text { Calculated Weight } \\
\text { of Importance (w) }\end{array}$ \\
\hline $\begin{array}{c}\text { Supervision Center } \\
\text { Information }\end{array}$ & $\mathrm{QV}_{\mathrm{C} 1}$ & 9.30 & 0.78 & 0.243 \\
$\begin{array}{c}\text { Visual Assessment } \\
\text { Ballast depth } \\
\text { (ballast pockets) } \\
\begin{array}{c}\text { Ballast fouling } \\
\text { (ballast quality) }\end{array}\end{array}$ & $\mathrm{QV}_{\mathrm{C} 2}$ & 5.60 & 1.19 & 0.146 \\
$\begin{array}{c}\text { Irregularities in } \\
\text { sub-ballast and } \\
\text { embankment fill }\end{array}$ & $\mathrm{QV}_{\mathrm{C} 3}$ & 8.40 & 0.91 & 0.219 \\
\hline
\end{tabular}

Taking into consideration the mean and standard deviation (SD) data from Table 6, the weight of importance for each attribute could be calculated. For example, the importance of ballast fouling Attribute $\left(\mathrm{C}_{4}\right)$ was calculated using Equation (8):

$$
\mathrm{w}_{4}=\frac{\mathrm{QV}_{\mathrm{C} 4}}{\sum_{\mathrm{i}=1}^{5} \mathrm{QV}_{\mathrm{C}, \mathrm{i}}}=\frac{8.70}{9.30+5.60+8.40+8.70+6.30}=0.227
$$


The sum of all weights of importance concerning attribute parameters, based on Equation (9), equals 1:

$$
\sum_{\mathrm{i}=1}^{5} \mathrm{w}_{\mathrm{i}}=0.243+0.146+0.219+0.227+0.164=1 .
$$

Finally, the overall utility function values $\mathrm{U}\left(\mathrm{S}_{\mathrm{j}}^{\mathrm{k}}\right)$ for each alternative was calculated by combining five weights of attribute importance with the normalized utility functions for the five $(n)$ attributes and the $(m)$ alternatives of specific section using Equation (10). The overall utility function values give the ranking for each alternative. For example, it is calculated for the fifth subsection within the first section:

$$
\mathrm{U}\left(\mathrm{S}_{5}^{1}\right)=\sum_{\mathrm{i}=1}^{5} \mathrm{w}_{\mathrm{i}} \cdot \overline{\mathrm{U}_{\mathrm{i}}}\left(\mathrm{S}_{5}^{1}\right) .
$$

After the overall utility function was calculated for each alternative within each section (railway line), the development of the final ranking list followed. A classification scheme, as shown in Table 4, was assigned to each subsection and the results are presented in the form, shown in Figure 7, for a $500 \mathrm{~m}$ length where the overall condition of the embankment was in the range from very poor to adequate and a second $500 \mathrm{~m}$ section where the overall condition of embankment was in the range from adequate to very good.

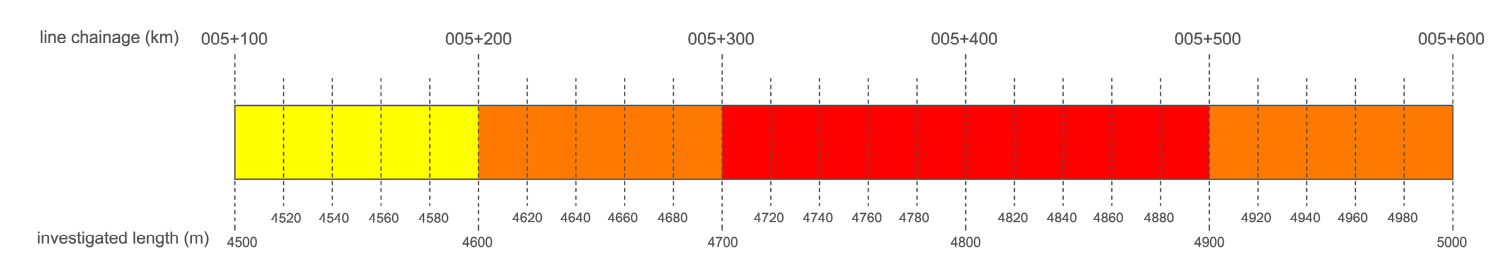

(a)

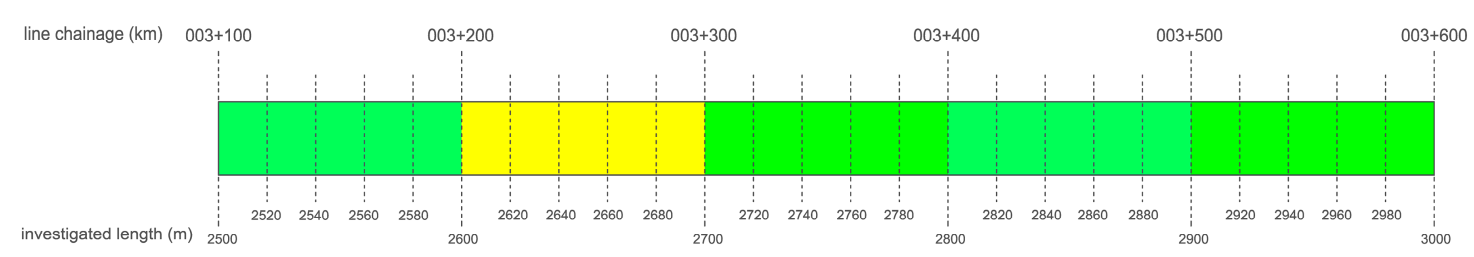

(b)

Figure 7. A graphical representation of: (a) a $500 \mathrm{~m}$ long line section with very poor to adequate condition and (b) a $500 \mathrm{~m}$ long line section with adequate to very good condition.

The implementation of the multi attribute utility theory thus provided classification of the condition for the investigated railway embankments. The overall classification results, given in Figure 8, represent the summation of classification results for lines selected by each Supervision Center (SC), as well as averaged values, in the form of an overall utility function-an overall percentage graph.

As it can be seen from Figure 8, the categorization results show that most of the investigated embankments, $41.8 \%$, are in an adequate condition and that $33.7 \%$ of the embankments are in poor condition, while $12.6 \%$ are in a very poor condition. On the other hand, $10 \%$ of the investigated embankments are in good condition, with only $1.9 \%$ is in a very good condition. The categorization results are consistent for line sections within each Supervision Center. The described procedure of implementing MAUT for railway embankment categorization gave the solid basis for decision-makers to plan further detailed investigation works and monitoring programs as well as remediation measures. 


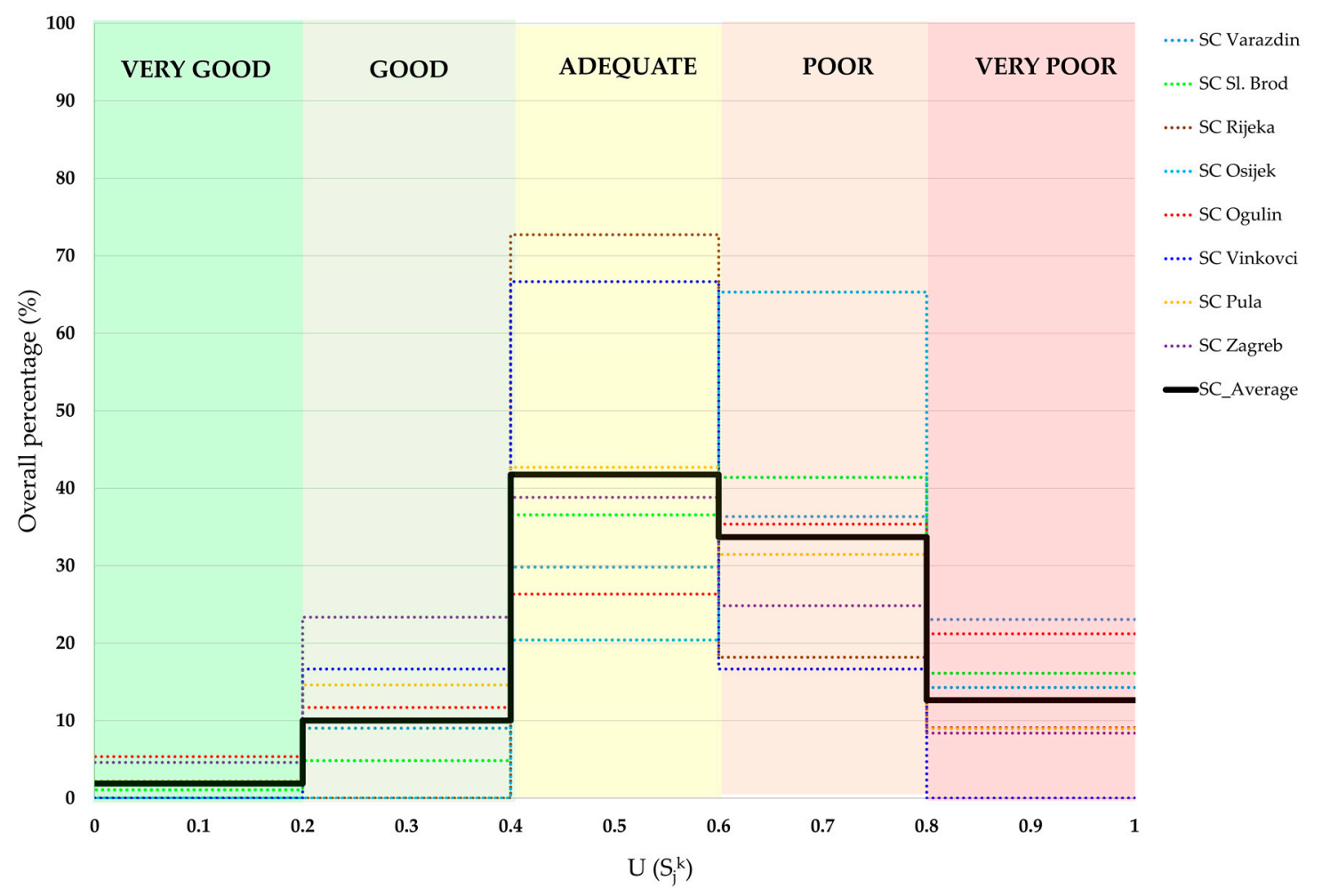

Figure 8. Overall utility function—overall percentage categorization summation results.

\section{Conclusions}

The paper presents a framework to apply the multi-attribute utility theory (MAUT) for the categorization of the condition of railway embankments using multiple sources of data available to the infrastructure managers. The overall methodology proposes the use of five attributes. These include frequency of tamping activities, extent of external irregularities obtained from visual inspections, frequency of internal irregularities obtained from GPR lower frequency data, ballast quality (fouling), and ballast depth (pockets). Ballast quality and depth data were obtained from higher frequency GPR antennas. The selection of these attributes is made because of their relevance to the problem and that they are readily available. By weighting the importance of each of the attributes and by evaluating them on the investigated railway lines, the MAUT-based methodology provides calculation of the overall utility function values used to form a ranking list of the condition for the investigated railway embankments. To verify the usefulness of the methodology, the paper presents its application on $181 \mathrm{~km}$ of railway embankments in Croatia. The calculated overall utility function for each section provided the categorization of embankments in five categories, ranging from very poor to very good. The developed MAUT model provides a transparent and comprehensive procedure that can support decision-makers to plan maintenance works and further detailed investigation works and monitor programs and remediation measures. The framework is flexible and methodology could be expanded to consider additional attributes.

Author Contributions: Conceptualization, M.S.K. and M.B.; Data curation, M.S.K.; Formal analysis, M.S.K. and M.B.; Investigation, M.S.K. and M.B.; Methodology, M.S.K. and I.S.; Project administration, M.S.K.; Validation, M.B., I.S. and K.G.; Visualization, M.B. and K.G.; Writing—original draft, M.B. and I.S.; Writing—review \& editing, M.S.K. and K.G.

Funding: The authors gratefully acknowledge the support from the H2020 Programme for DESTination RAIL project, funded under MG-2.1-2014 I²I Intelligent Infrastructure call, grant agreement No 636285.

Conflicts of Interest: The authors declare no conflicts of interest. 


\section{References}

1. Gavin, K.G.; Xue, J.F. Use of a genetic algorithm to perform reliability analysis of unsaturated soil slopes. Geotechnique 2009, 59, 545-549. [CrossRef]

2. Garramiola, F.; Poza, J.; Madina, P.; Del Olmo, J.; Almandoz, G. A Review in Fault Diagnosis and Health Assessment for Railway Traction Drives. Appl. Sci. 2018, 8, 2475. [CrossRef]

3. Kovacevic, M.S.; Gavin, K.; Stipanovic Oslakovic, I.; Bacic, M. A New Methodology for Assessment of Railway Infrastructure Condition. Transp. Res. Procedia 2016, 14, 1930-1939. [CrossRef]

4. Dhillon, B.S. Engineering Maintenance: A Modern Approach; CRC Press: Boca Raton, FL, USA, 2002.

5. Wu, Y.; Qin, Y.; Wang, Z.; Jia, L. A UAV-Based Visual Inspection Method for Rail Surface Defects. Appl. Sci. 2018, 8, 1028. [CrossRef]

6. Woodward, D.G. Life cycle costing-Theory, information acquisition and application. Int. J. Proj. Manag. 1997, 15, 335-344. [CrossRef]

7. Kendall, A.; Keoleian, G.; Helfand, G. Integrated Life-Cycle Assessment and Life-Cycle Cost Analysis Model for Concrete Bridge Deck Applications. J. Infrastruct. Syst. 2008, 14, 214-222. [CrossRef]

8. Kabir, G.; Sadiq, R.; Tesfamariam, S. A review of multi-Attribute decision-making methods for infrastructure management. Struct. Infrastruct. Eng. 2014, 10, 1176-1210. [CrossRef]

9. Breemer, J.; Al-Jibouri, S.H.S.; Veenvliet, K.T.; Heijmans, H.W.N. RAMS and LCC in the Design Process of Infrastructural Construction Projects: An Implementation Case; University of Twente: Enschede, The Netherlands, 2010; pp. 1-18.

10. Panjamani, A.; Bharatha, T.P.; Amarajeevi, G. Study of Ballast Fouling in Railway Track Formations. Indian Geotech. J. 2012, 42, 87-99. [CrossRef]

11. Funtul, S.; Fortunato, E.; De Chiara, F.; Burrinha, R.; Baldeiras, M. Railways Track Characterization Using Ground Penetrating Radar. Procedia Eng. 2016, 143, 1193-1200. [CrossRef]

12. Di Prinzio, M.; Bittelli, M.; Castellarin, A.; Rossi Pisa, P. Application of GPR to the monitoring of river embankments. J. Appl. Geophys. 2010, 71, 53-61. [CrossRef]

13. Cai, J.Q.; Liu, S.X.; Fu, L.; Feng, Y.Q. Detection of railway subgrade moisture content by GPR. In Proceedings of the 16th International Conference on Ground Penetrating Radar (GPR), Hong Kong, China, 13-16 June 2016; pp. 1-5. [CrossRef]

14. Sussmann, T.; Selig, E.T.; Hyslip, J.P. Railway track condition indicators from ground penetrating radar. NDT E Int. 2003, 36, 157-167. [CrossRef]

15. Donohue, S.; Gavin, K.; Tolooiyan, A. Geophysical and geotechnical assessment of a railway embankment failure. Near Surf. Geophys. 2011, 9, 33-44. [CrossRef]

16. Burrows, A.; Lockwood, M.; Borowczak, M.; Janak, E.; Barber, B. Integrated STEM: Focus on Informal Education and Community Collaboration through Engineering. Educ. Sci. 2018, 8, 4. [CrossRef]

17. Grout, I. Remote Laboratories as a Means to Widen Participation in STEM Education. Educ. Sci. 2017, 7, 85. [CrossRef]

18. Von Neumann, J.; Morgenstern, O. Theory of Games and Economic Behavior; Princeton University Press: Princeton, NJ, USA, 1945.

19. Patidar, V.; Labi, S.; Sinha, K.; Thompson, P.D. Multi-Objective Optimization for Bridge Management Systems; National Cooperative Highway Research Program Report 590; Transportation Research Board of the National Academies: Washington, DC, USA, 2007.

20. Fishburn, P.C. Utility Theory for Decision Making; Research Analysis Corporation: McLean, VA, USA; John Wiley \& Sons: Hoboken, NJ, USA, 1970.

21. Allah Bukhsh, Z.; Stipanovic Oslakovic, I.; Klanker, G.; O' Connor, A.; Doree, A.G. Network level bridges maintenance planning using Multi-Attribute Utility Theory. Struct. Infrastruct. Eng. 2018, 872-885. [CrossRef]

22. Cerić, A. Trust in Construction Projects; Routledge: Abingdon, UK; Taylor \& Francis Group: Didcot, UK, 2015.

23. Brauers, W.K.M.; Zavadskas, E.K.; Peldschus, F.; Turskis, Z. Multi-objective decision-making for road design. Transport 2008, 23, 183-193. [CrossRef]

24. Zavadskas, E.K.; Liias, R.; Turskis, Z. Multi-Attribute Decision-Making Methods for Assessment of Quality in Bridges and Road Construction: State-Of-The-Art Survey. Balt. J. Road Bridge Eng. 2008, 3, 152-160. [CrossRef] 
25. Dabous, S.A.; Alkass, S. A multi-attribute ranking method for bridge management. Eng. Constr. Archit. Manag. 2010, 17, 282-291. [CrossRef]

26. Abu-Samra, S.; Zayed, T.; Tabra, W. Pavement Condition Rating Using Multiattribute Utility Theory. J. Transp. Eng. Part B Pavements 2017, 143. [CrossRef]

27. Zietsman, J.; Rilett, R.L.; Kim, S.J. Transportation corridor decision-making with multi-attribute utility theory. Int. J. Manag. Decis. Mak. 2006, 73, 254-266. [CrossRef]

28. Barić, D.; Radačić, Ž.; Čurepić, D. Implementation of multi-attribute decision-making method in selecting the railway line for reconstruction. In Proceedings of the International Conference on Traffic Science ICTS 2006 “Transportation Logistics in Science and Practice", Portorož, Slovenia, 5-7 December 2006; Zanne, M., Fabjan, D., Janček, P., Eds.; Fakultet za Pomorstvo in promet: Portorož, Slovenia, 2006; pp. 1-5.

29. Ivic, M.; Markovic, M.; Belosevic, I.; Kosijer, M. Multi Attribute decision-making in railway route planning and design. Građevinar 2012, 64, 195-205. [CrossRef]

30. Garmabaki, A.H.S.; Ahmadi, A.; Ahmadi, M. Maintenance Optimisation Using Multi-Attribute Utility Theory. Current Trends in Reliability, Availability, Maintainability and Safety: An Industry Perspective; Kumar, U., Ahmadi, A., Verma, A.K., Varde, P., Eds.; Springer International Publishing: Cham, Switzerland, 2016; pp. 13-25. [CrossRef]

31. Jajac, N.; Knezić, S.; Marovic, I. Decision support system to urban infrastructure maintenance management. Organ. Technol. Manag. Constr. 2009, 1,72-79.

32. Tennakoon, N.; Indraratna, B.; Rujikiatkamjorn, C.; Neville, T. The Role of Ballast Fouling Characteristics on the Drainage Capacity of Rail Substructure. Geotech. Test. J. 2012, 35, 1-12. [CrossRef]

33. Al-Qadi, I.L.; Xie, W.; Roberts, R. Scattering analysis of ground-penetrating radar data to quantify railroad ballast contamination. NDT E Int. 2008, 41, 441-447. [CrossRef]

34. Selig, E.T.; Waters, J.M. Track Geotechnology and Substructure Management; Thomas Telford: London, UK, 1994.

35. Long, Z.J.; Xing, B.; Liu, H.; Liu, Q. Hyperbola Recognition from Ground Penetrating Radar Using Deep Convolutional Neural Networks. In Proceedings of the 2nd International Conference on Artificial Intelligence: Techniques and Applications (AITA 2017), Shenzen, China, 17-18 September 2017; pp. 11-13. [CrossRef]

36. Yakowitz, D.S.; Lane, L.J.; Szidarovszky, F. Multi-attribute decision making: Dominance with respect to an importance order of the attributes. Appl. Math. Comput. 1993, 54, 167-181. [CrossRef]

37. Keeney, R.; Raiffa, H. Decisions with Multiple Objectives: Preferences and Value Tradeoffs; Cambridge University Press: Cambridge, UK, 1993.

38. Dyer, J.S. Maut-Multiattribute Utility Theory. In Multiple Criteria Decision Analysis: State of the Art Surveys; International Series in Operations Research \& Management Science; Springer: New York, NY, USA, 2005; Volume 78.

39. Lajnert, S. An overview of the organization and operation of Croatian Railways in the Homeland War. Arh. Vjesn. 2007, 50, 131-174. (In Croatian)

40. HZ Infrastruktura. Available online: www.hzinfra.hr (accessed on 22 September 2019).

(C) 2019 by the authors. Licensee MDPI, Basel, Switzerland. This article is an open access article distributed under the terms and conditions of the Creative Commons Attribution (CC BY) license (http://creativecommons.org/licenses/by/4.0/). 